Circular 1438

\title{
Toolkit for Implementing a Community-Based "IMBY" Safety Event
}

Carol Lehtola and Charles Brown

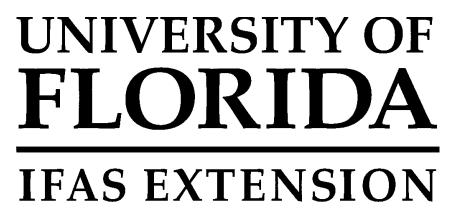


This document is CIR 1438, one of a series of Florida AgSafe, a program in the Agricultural and Biological Engineering Department, Florida Cooperative Extension Service, Institute of Food and Agricultural Sciences (IFAS), University of Florida. First published April 2003. Additional copies of this publication are available at the Florida AgSafe Web site: <http://www.flagsafe.ufl.edu>. For the complete range of publications available from the Florida Cooperative Extension Services, please visit the EDIS Web site: $<$ http://edis.ifas.ufl.edu>.

The authors - Carol J. Lehtola, associate professor and State Extension Agricultural Safety Specialist, and Charles M. Brown, Coordinator for Information/Publication Services, Agricultural and Biological Engineering Department, Institute of Food and Agricultural Sciences (IFAS), University of Florida, Gainesville, 32611.

IFAS, the Institute of Food and Agricultural Sciences, is an equal opportunity/affirmative action employer authorized to provide research, educational information and other services only to individuals and institutions that function without regard to race, color, sex, age, handicap, or national origin. For information on obtaining other Extension publications, contact you county Cooperative Extension Service office.

Florida Cooperative Extension Service / Institute of Food and Agricultural Sciences / University of Florida / Christine Taylor, Waddill, Dean. 


\section{Contents}

Introduction $\quad 5$

Seize the Moment $\quad 7$

Task 1: Assemble a Committee $\quad 7$

Task 2: Identify Community Resources $\quad 7$

Task 3: Develop Community Support $\quad 8$

Making the Contacts

The Kick-Off Meeting

Task 4: Schedule and Publicize the Event

Scheduling the Event

Marketing and Publicizing the Project

Positive Emphasis

Get Practical

Press Releases

Task 5: Conduct the Event

Your Next Event?

Resources

Toolkit

Key Contact List

Kick-Off Meeting

Suggested Agenda for Kick-Off Meeting

Marketing and Publicizing the Event

IMBY Invitation (sample; download at Florida AgSafe Web site)

Letter of Invitation for Participants

Letter of Invitation for Supporters

Press Release (before event)

Press Release (after event)

Participant's Evaluation

Certificate of Completeion

Follow-up Meeting 
Toolkit for Implementing a Community Based "IMBY" Safety Event 


\section{Introduction}

This publication provides guidance and materials to help implement a safety workshop using the video "Rhythm of the Seasons: A Journey Beyond Loss" and the In My Back Yard (IMBY) Home and Farm Hazard Hunt workbook. These guidelines also can be useful for developing other safety events.

A specific lesson plan for the IMBY Workshop is provided in a companion publication, "Rhythm of the Seasons: Planting Seeds of Safety, Harvesting Grains of Hope - A Lesson Plan for Farm Safety Audiences" (see the Resources section of this publication).

In this publication, putting the IMBY event together is broken out into a series of specific tasks:

Task 1 - Putting together a team to develop the event

Task 2 - Identify community resources

Task 3 - Develop community support

Task $4-$ Schedule and publicize the event

Task 5 - Conduct the event

Task 6 - Evaluate the effort

In addition to guidelines for each task, this publication includes forms - the toolkit, which organizers can use as given or customize for specific communities, audiences, or events. The toolkit consists of:

- Key Contact List (who can help and how can they help)

- Kick-Off Meeting

- Suggested Agenda for Kick-Off Meeting

- Marketing and Publicizing the Project

- IMBY Invitation (sample; download at Florida AgSafe Web site)

- Letter of Invitation for Participants

- Letter of Invitation for Supporters

- Press Release (before event)

- Press Release (after event)

- Participant's Evaluation

- Certificate of Completion (color version available on Florida AgSafe Web site)

- Follow-up Meeting 
The goal of the IMBY activity - as in any educational effort - is to change people's behaviors. To achieve this, the activity must accomplish a short list of goals:

- Make people aware that unintentional injuries and deaths are preventable.

- Give information about the specific nature of the hazards.

- Give information about eliminating hazards.

- Provide a procedure for hazard identification and elimination.

\section{Suddenly Aware of Safety}

Often, people are not very aware of safety. As long as nothing "bad" happens to them, they tend to feel that they are safe enough, but the elements of a hazard that can lead to serious injury or death might be all around them, waiting to spring shut like a trap. Agricultural work has many such hazards, but these hazards are well known from a long history of careful study. Some of them are obvious, but farmers are used to working around them and "factor them in" during their work day - perhaps they feel that certain hazards are just part of the job. Other hazards are not obvious, and are encountered suddenly when a worker is thrown into an unfamiliar situation. Obvious or not, it only makes sense to learn what the hazards of any job or workplace are and do something about them.

Hazards lead to what are often called accidents, but for purposes of this publication, the term "incident" will be used. It is an important choice of terms, because the word "accident" implies that nothing could have been done to prevent the injury or death... and nothing could be farther from the truth. The great majority of farm injuries and deaths can be prevented through the elimination of hazards and incorporation of better safety practices. More often than not, incidents are "accidents waiting to happen," that is to say that when people think back over the circumstances of an incident, it becomes clear that somewhere in the chain of events that led to a death or injury, there was an act of carelessness or some equipment that should have been repaired or replaced.

Until someone is injured or killed, farmers, their families and employees often accept the status quo. But when a community is shaken by the loss of a hard-working farmer or tragic injuries to a child in a farm incident, there's a moment when everyone asks "how did this happen". That's a teachable moment, and it may not last long. Community energy will soon turn to supporting the family in their loss or in paying their medical bills, and the prevention questions, "How did this happen" and "How can we keep it from happening again," will be replaced by the feelings of inevitability, "These things happen" and "Life moves on." 


\section{Seize the Moment}

It does not necessarily take an incident to get the ball rolling. Anyone who cares about safety around the farm and home can initiate a community safety event, but supporters and helpers will be needed.

Supporters and helpers do more than make the event happen; they are a critical part of community acceptance and involvement of the activity and its message. Many studies have found that this community-based approach is the most successful. Studies have also indicated that people seek safety information from community businesses and various professionals. The involvement of these key people will encourage others to participate in the event.

\section{Task 1: Assemble a Committee}

One person probably cannot and should not try to develop and conduct the workshop alone. Instead, that person should find other people who share this concern and form a committee to develop and deliver the safety event to the community. This group then:

- Decides on its goal (in this case, developing a safety event)

- Identifies the individual tasks that must be done to accomplish this goal

- Divides responsibility for the tasks

- Follows through to complete each task

It is important for committee members to have good communication through regular meetings (formal or informal) or conversations as the project develops. If this is the first such event the committee has put together, it is a good idea to keep the arrangements fairly simple. Enthusiasm can lead to some elaborate planning, but stay focused on the goal of delivering a successful safety event.

\section{Task 2: Identify Community Resources}

There are many organizations in any community that have a vested interest in the health and well-being of farmers and farm families. There's the medical community, the business community, the insurance community, and of course, the farmers themselves. All of these groups know that "an ounce of prevention is worth a pound of cure," but often their professional focus is on the cure, and they do not become involved with someone's health and safety until it has already been compromised. Motivation - and a little organization - is needed to get community members focused on prevention. 
Community resources can help in all sorts of ways with a safety event. They can:

- Provide a venue

- Contribute money to defray costs

- Contribute favors, give-aways, prizes, or rewards

- Send participants to the event

- Provide volunteers

- Promote the event

Use the Key Contact List included in the toolkit to identify individuals and organizations in the community that might have some interest in the safety event. Do not assume that anyone is too busy, too important, etc. - you never know until you ask! It can be surprising who will think the event is a great idea AND is eager to make a contribution of some kind.

The toolkit contains a sample Letter for Supporters that can be used as a model. Make up a letter requesting support based on the one provided. It is very important to follow up on these letters. Try to follow up with potential supporters by phone. There might be some negative answers, but there will also be positive answers. Think of it this way: Calling people makes it easier for them to say yes.

\section{Task 3: Develop Community Support}

\section{Making the contacts}

The committee members have to get down to real work at this point. They will have to decide who is going to contact whom on the Contact List. Let contacts know exactly what the event will include, and if they are interested, tell them that they will be contacted again to send a representative to the Kick-Off organizational meeting.

When calling contacts about farm safety, it is helpful to remember that the statistics have already done some of the work. Almost everyone in a farming community will know someone who has suffered a severe incident, and therefore will understand the need for the event.

It is important to make clear that the event is not an effort by one faction of the community to "teach" another faction, but it is something that the entire community can come together on. 


\section{The Kick-Off Meeting}

The Kick-Off meeting is an opportunity for the committee and other interested persons volunteers and supporters - to get together. In the toolkit, there are two forms that pertain to the Kick-Off Meeting: a schedule form and an agenda.

On the schedule form, several objectives for the Kick-Off Meeting are listed:

- Expand awareness of the issues

- Clarify program objectives and procedures

- Provide technical support by introducing resources available locally

- Provide a social support network of peers and community

- Reinforce information presented in program materials

- Develop sense of program ownership

- Identify effective program marketing strategies

Be sure to invite your resource organizations and businesses to send representatives. Make them part of the event from the beginning and let them know how important they are to the effort. This helps them to develop a feeling of "ownership" of the event, and helps motivate them in working with the planning.

Keep the meeting moving. There will be a lot of decisions to make, but remember to get specific about the work that needs to be done, and get it assigned.

Think in terms of the specific parts of the event and get volunteers to take responsibility for getting each task done.

\section{Task 4: Schedule and Publicize the Event}

\section{Scheduling the Event}

Be aware of the intended audience. The event might be less successful if it is for "everyone" than if there are specific groups that can be targeted. Having those groups in mind can help in picking a good time for the event

Be aware of other events, such as holidays or sport, civic, or professional events. Other events can work for or against the safety event. If the safety event is at the same time as a big sports event, it might be that most people will attend that event or stay home and watch it on television. But other events that are safety or civic related might make good 
partners. An event for children might give parents a couple of hours when they could attend the IMBY workshop.

Surely, the committee is "fired up" about safety, and they want to get the word out now. But each step leading up to the event needs to be given proper time. Although the safety event is important, not everyone will have the same sense of urgency, and it takes time for the committee to get information, make decisions, and do the work. All of this is probably being done by volunteers who have other things going on in their lives. There needs to be plenty of lead time, as well, to get the word out through the media.

\section{Marketing and Publicizing the Project}

The toolkit contains a form to help you market and publicize the event. Marketing and publicity are different activities, but they work hand-in-hand.

Identify Target Audiences - Those who know how important the message of the safety event is will want everyone to participate, so why not invite everyone? Realistically, there will be a limited budget, limited time, limited volunteers, and limited space. The event will be more successful if the people who need the message most and are most interested are there - these people are your target audiences. In a particular community, maybe it is farm parents, or homeowners, or farmers, or employers, or suppliers, and so on. Maybe the event should target several of these audiences. Sit down with the committee and think through who the target audiences in their community for this particular event should be.

Develop a Marketing Strategy - Once a list of the target audiences has been made, what is needed is a strategy for reaching them. Think it through from their point of view: What media do they tend to use to get information? What media or personalities do they find most believable? These are marketing questions. Once they are answered, think about how best to use the media you've decided on and how to actually get the message to these people. Those are publicity issues.

Marketing is about who to get the message to and what the message should be. Publicity is the work of actually getting the message to the target audiences.

Marketing can help decide what to include in publicity. Is the main goal to attract farmers to the event? How about businesses or employers? Many people might be interested in the event if a local personality is involved in some way. People attend events for all sorts of reasons. Knowing something about what those reasons are and making sure they are mentioned in the event publicity is an important part of marketing. 
What are some of these reasons to attend? Sit down with the committee and discuss what would get their interest and really encourage them to attend. Write these ideas down as elements for event publicity. These are good "talking points" as well if committee members are interviewed by a reporter or want to write an article for a newsletter or newspaper.

Get the Word Out - With publicity, the goal is to tell people about the event. An ad in the local paper or maybe a message on local television or radio are good ideas. (Note: Ads usually cost money; it's cheaper to try and get the local media to do a story about the event.) Recent community incidents were probably reported through one of these media; since the media report when there is a problem, it seems only reasonable that they should report when there is a solution. That is exactly what the safety event is: it is part of a solution. Many newspapers and television news broadcasts have a "neighbors" section or a "good news" section that might be perfect for a story about a community-sponsored safety event. Keep in mind that media are very "image" driven, that means they like to have pictures. If your story comes with some good visuals, it is much more likely to be covered. For example, if a local youth group is going to get together to address invitations to the event, call the local television station and let them know. A little video footage of happy volunteers working on a worthwhile project might be just what they are looking for to cap off the evening news.

The toolkit contains a form to help plan marketing and publicity. When you've decided on target audiences, think about specific media that reach that audience; write that under medium on the form. What does that medium require? A 20-second script, a few photographs, an interview? What committee member can make it happen? (It's helpful if someone on the committee has a contact at the radio station, newspaper, etc.)

Target Individuals with Invitations - So far, publicity has been presented in terms of mass media. When the message gets into the newspaper or onto radio, whoever hears or reads it gets the message. However, if a list of names exists, as for a religious or civic group, invitations can be sent directly to potential event participants. The toolkit contains an Invitation for Participants, which can be used as a model.

Invitations can be helpful to mobilize groups that wish to help. Groups need specific projects, and one way they can help is to photocopy, address and distribute invitations. For example, a youth group at a church may want to have a get-together to sign and address invitations to the rest of the members of the church. Invitations can be effective when used within a group because people are more likely to take an interest in something if people they know and feel they have something in common with are already interested. 


\section{Positive Emphasis}

When people become aware of how preventable most farm injuries or deaths are, they will probably wonder "why doesn't somebody do something about this?" The facts about preventable injury and death can cause anger and indignation. Those are appropriate feelings when lives are being needlessly damaged or lost. However, these feelings may not be the most productive for motivating people to attend your event.

As justified as anger or outrage may be, other people may associate these expressions with bad feelings or guilt. People usually do not want to feel bad and instinctively withdraw from messages that make them feel that way. Also, when the subject is death or injury, many people do not want to think about the possibility of these things happening. It may seem childish to some, but many people do not like to think about something they wish will never happen.

The point is to channel energy about this important subject into positive expressions. Talk about solutions. Help people feel that the event empowers them to make a positive change in their lives and in the lives of the people around them. Safety is more than preventing death and injury, it is also about taking a positive, proactive approach to life. Having a safety attitude does not mean worrying more, it means being more aware and taking appropriate precautions. That should allow people to worry less.

Messages about death and injury should be appropriately serious, but when they are too emotional, people can feel manipulated and turn off the message. If they do not want the message, surely they will not attend the event to hear more of the same.

The centerpiece of the IMBY workshop is a video in which something very sad happens - a child dies. In the video, viewers are brought face-to-face with the mother of this child. Many viewers will be moved to tears. However, the video does not end with a tragic loss and anguish. The video takes the viewer through the recovery experience as well. The video is not a lecture about grief; the idea is to point the way to recovery and finding purpose and meaning in life again after a great loss.

Adults probably already realize that preventable death and injury are sad, tragic events, but many people will retreat to a position of "what can we do?" What people may not realize is that "preventable" means just that - there is something they can do. 


\section{Get Practical}

This happens all the time... someone prepares a great ad for the local paper about an event and they forget to include the time or place. When preparing publicity, ask other committee members to review the details of ads, articles, talking points, or speeches.

If the committee had unlimited funds, it could do all sorts of publicity, fly in celebrities, etc., but usually committees for safety events are working with small budgets, so it is very important to identify potentially free or low cost forms of advertising. Photocopy a flier and post them in the windows of businesses where the people who would be most interested in the event will see them. Businesses, religious groups, civic groups - all these are possibilities.

\section{Press Releases}

A common way for organizations to inform the press about activities is through press releases. A press release is a "heads up" for news organizations. The idea of a press release is to entice a news organization into doing a story about an interesting local event. It invites them to contact the organization for more information. Press releases are often distributed by fax, but mail or hand delivery work just as well. Send your press release to every media representative you can think of - local newspapers, television and radio stations, local magazines, weeklies, etc. Try to send it to a specific staff person if possible, and preferably, someone who has a definite interest in your event.

The toolkit contains two press releases. The first one goes out before the event to let the press know that it is going to happen, and the second goes out after the event to let the press know that the event happened and what its successes were. It might be that the event doesn't capture someone's imagination before it takes place, but an interesting event can create "buzz", and media may be more interested in it after it has created some interest. This follow-up press release is another way to get out the message.

\section{Task 5: Conduct the Event}

A lesson plan for the workshop itself is contained in a separate publication titled "Rhythm of the Seasons: Planting Seeds of Safety, Harvesting Grains of Hope - A Lesson Plan for Farm Safety Audiences." See the Resources section of this publication.

The toolkit provides two forms that may be useful at the conclusion of the event. People may make verbal comments about the event, but it is helpful if they evaluate the safety 
event on a simple form. It is not necessary to try to get lengthy answers. The Evaluation Form provided encourages participants to give quick impressions of the event they have just experienced. Compiling these evaluations can be very informative and probably very encouraging. Having evaluations is more helpful generally than committee members comparing impressions.

Evaluations are also helpful as a formal way of showing that the event was well received and had a positive impact. That kind of proof will be very useful when you need support for your next event. Quotes taken from the evaluations can be useful in follow-up publicity.

The toolkit also contains a Certificate of Completion. Use the certificate as is or use it as a model. Some committees make arrangements for these certificates to be ready for participants as they leave, but others send the certificates to the participants in the days after the event. The certificate can be significant to some people, for others it represents appreciation for their attendance. It is like a thank-you note, and reminds people that the event was a positive and beneficial experience. If people post the certificate - on a refrigerator at home or in a workplace - it then becomes a form of publicity for family members, friends, and coworkers. (A color version of the certificate is available on the Florida AgSafe Web site.)

\section{Task 6: The Follow-Up Meeting}

Last but not least, the toolkit contains an agenda for the follow-up meeting. Have this meeting as soon after the event as possible, while everyone's experience is fresh. The follow-up meeting is very important.

The follow-up meeting is a chance for committee members to discuss with one another what they have accomplished, ask specific questions of resource people, develop further action plans specific to their community, evaluate what they have learned and changed, make recommendations for what they would do differently in presenting a similar program, and recognize and reward accomplishments.

The follow-up meeting could be designed to be either just a follow-up for the committee itself - or as the suggestions below indicate - it could be for the program participants several weeks or months after the event. If the follow-up meeting includes participants, use it as an opportunity for people to report on what they have accomplished from their IMBY list of action items. If hazards were corrected as part of a group project or program, for example, $4-\mathrm{H}$, the follow-up could be held at one of their regularly scheduled meetings. 
The follow-up meeting is also a good opportunity for the committee members to relax together and celebrate their accomplishment. Everyone has worked to produce a successful event. Bringing this information to your community is a major success in itself.

Here are some other ideas for the follow-up meeting:

- A meal could be included, perhaps coordinated through a local commodity organization or other sponsoring group.

- A guest speaker could summarize changes people have made and provide ideas to other participants.

- Awards or incentive packages could be provided to those who correct a certain number of hazardous items.

\section{Your Next Event?}

The day after the event is over will be a time to think about all the good that was accomplished through the group's efforts. Committee members will probably share with each other as they hear reports from others about the difference the event made in the participant's daily lives.

Conversation may soon turn from the recent past to the future. Putting on one event often gives ideas, inspiration and motivation to do another one. One event leads to another and soon a continuing community safety program is in place.

Businesses and organizations that supported this event will probably be willing to help with others, as long as there is enough time between events - all these groups have other obligations, as well as the work they do.

At the follow-up meeting, ask your committee members when they think the next event should be. Perhaps put on another IMBY workshop for a different group of people, or find some materials to create a special safety workshop for your community. There are plenty of materials and safety specialists available to give additional guidance. Contact the local county Extension office or public health agency for a referral.

All any community needs to be safer and healthier is a few concerned individuals to get the ball rolling. 


\section{Resources}

Additional copies of this publication and other materials for the IMBY Home and Farm Hazard Hunt Workshop are available over the World Wide Web at Florida AgSafe, the Web site of the Florida Agricultural Safety Program, <www.flagsafe.ufl.edu> :

- Rhythm of the Seasons: Planting Seeds of Safety, Harvesting Grains of Hope - A Lesson Plan for Farm Safety Audiences.

- Rhythm of the Seasons: Planting Seeds of Safety, Harvesting Grains of Hope - A PowerPoint Presentation to accompany the Lesson Plan 


\section{Key Contact List}

Educational efforts for safety have more impact when there is community involvement and support in organizing and carrying out the project. Below is a list of potential contacts who may be interested in participating or supporting this project. Communities vary as to which services are available and which are most active. These are just suggestions; customize this list for your community.

Agricultural and rural health/safety clinics Agricultural and rural organizations

Commodity groups

Community colleges

Cooperatives

Cooperative Extension Service

Farm business consultants

Farm business managers

Farm equipment and supply dealers

Local chapter of Farm Safety 4 Just Kids

Groups in our community that can help:
Local chapter(s) of FFA

Local 4-H club(s)

Local youth group(s)

Financial institutions

Hospitals and health professionals

Insurance companies

Utility companies

Wellness programs

Veterinarians

Fire departments

Civic groups 


\section{Kick-Off Meeting}

Time, place, date of meeting

Kick-off meeting chairperson

Other committee members:

A kick-off meeting can achieve the following objectives:

1) Expand awareness of the issues

2) Clarify program objectives and procedures

3) Provide technical support by introducing locally available resources

4) Provide a social network of peers and community

5) Reinforce information presented in program materials

6) Develop sense of program ownership

7) Identify effective program marketing strategies

\section{Objectives for Kick-Off Meeting:}

1.

2.

3.

4.

5.

6. 


\section{Suggested Agenda for Kick-Off Meeting}

I. Welcome and Introduction

II. Description of the Program
A. What it covers
B. Target audience
C. What is to be accomplished
D. Who are the contacts and who is responsible for doing what
E. Other program items including follow-up meetings, news releases, etc.
F. Contests, awards, games, prizes, food, etc. that may be incorporated into the event

III. Local resources and support available

IV. Question and answer

V. Other issues

VI. Adjourn (make certain everyone is clear on what they have volunteered to do)

\section{Agenda for your Kick-Off Meeting:}




\section{Marketing and Publicizing the Event}

Marketing and publicity committee chairperson

Other committee members:

The key to effective publicity is to use a variety of methods - fliers, radio spots, interviews, etc. There are many possibilities - be creative!

Double check your fliers, print materials, speech and interview notes: Do they contain the essential information - Title of the event, Date, Time, Place, Cost, Brief statement of the purpose of the event, Sponsors, Food and Drink, Special personalities.

\section{Marketing and publicity strategy:}

Medium

Task

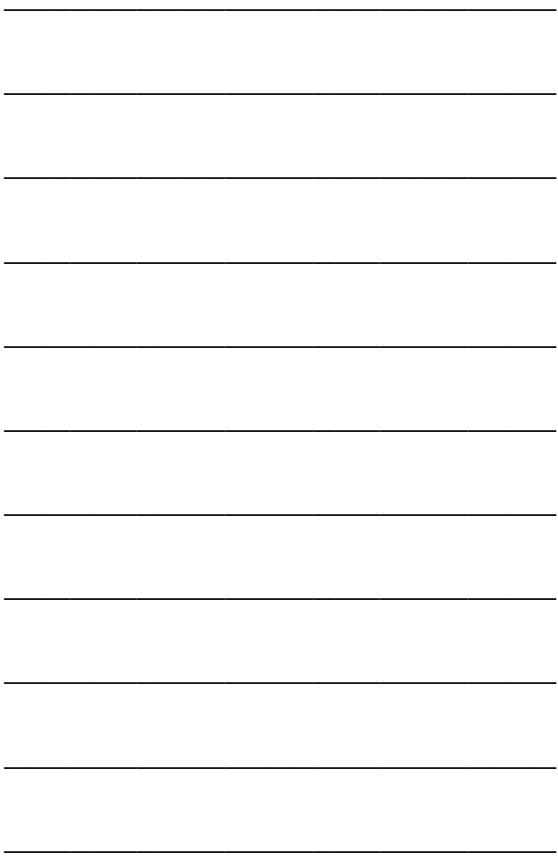

Person responsible 


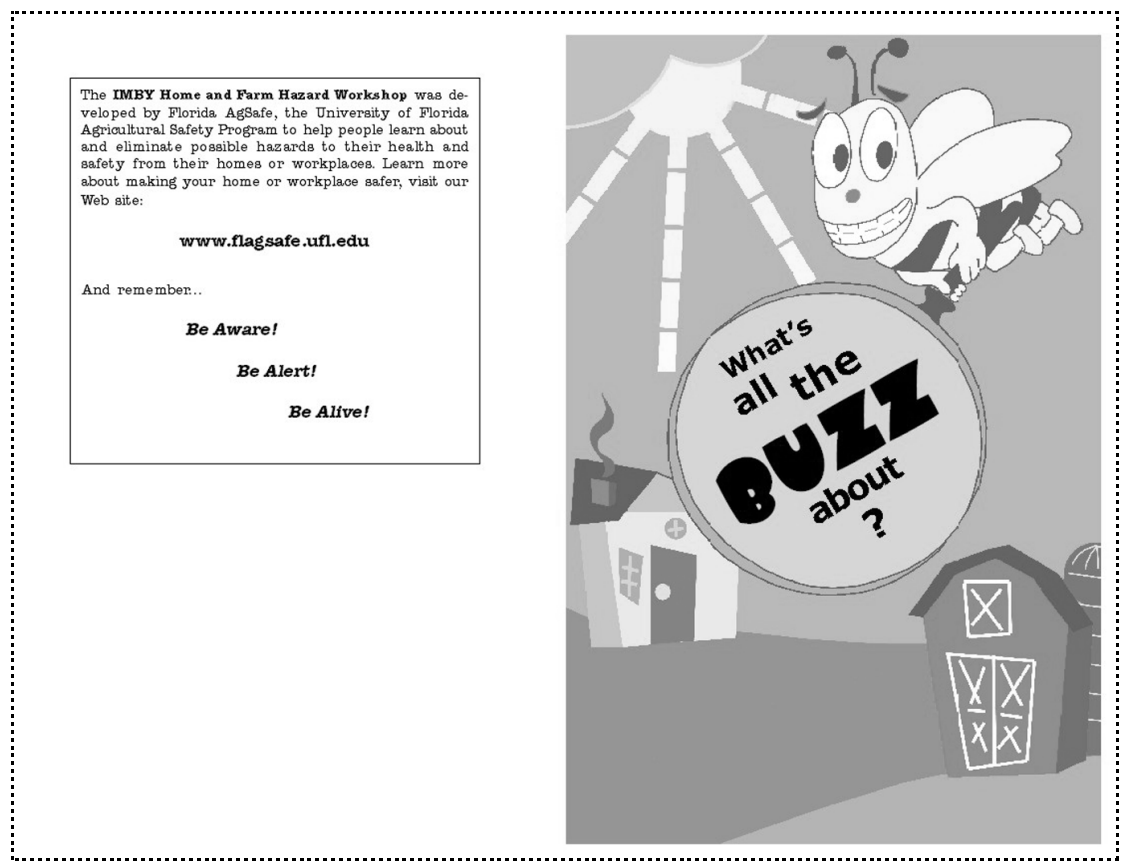

IMBX Home and Farm Hazard Hunt Workshop features a video in which a mother tells the true story the loss of her 11 . year-old son in a farm-re lated incident. This story will motivate you to take action to make your home or farm a safer, healthier place. After. the video, there will be a presentation about specific ways to improve safety in your home/farm environment. The presentation will include development of an "action plan" that you can take home and use with your family to get all those trouble spots taken care of.. probably things you've been meaning to do! And maybe a few you weren't aware

We look forward to presenting this valuable program to you. Together with your interest and participation, we can make our community a healthier and safer place to live and work.

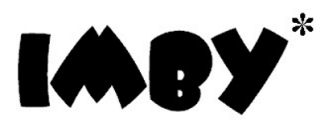

Farm and Home Safety Hazard Workshop

Make your home or workplace safer. Join your friends and neighbors to take the safety challenge!

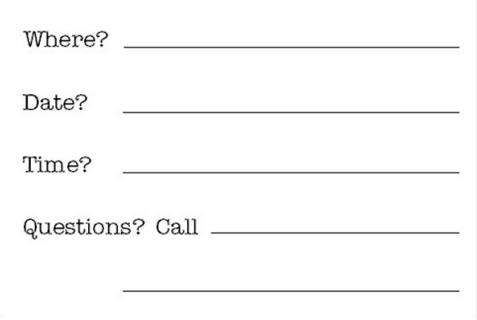

* In IMy Back Yard (where safety should start)

IMBY Invitation - The upper image shows the front/back of the IMBY invitation, and the lower image shows the inside. The invitation is shown here at reduced size. The actual size of the invitation is standard $81 / 2 " x 11^{\prime \prime}$. A color version can be downloaded at the Florida AgSafe Web site: $<$ www.flagsafe.ufl.edu $>$. 


\title{
Letter of Invitation for Participants
}

\author{
[Date]
}

Dear

Home and farm safety and health issues have been the focus of media attention, business promotions, FFA and 4-H youth activities, and Extension programs. These efforts have been very effective in making people more aware of risks and hazards at home or work.

As a community, we are concerned about the safety and health of our citizens. Because of this concern, we invite all adults and children, both rural and urban, to take part in the IMBY Home and Farm Hazard Hunt Workshop. This workshop is a means for local residents to develop safety action plans that they can apply to their own home, acreage, farm, or workplace. (IMBY stands for "In My Back Yard" - the proper place to start practicing safety.)

The IMBY Home and Farm Hazard Hunt Workshop features a video in which a mother tells the true story of the loss of her 11 -year-old son in a farm-related incident. This story will motivate you to take action to make your home or farm a safer, healthier place. After the video, there will be a presentation about various specific ways to improve safety in your home/farm environment. The presentation will include development of an "action plan" that you can take home and use with your family to get all those trouble spots taken care of... probably things you've been meaning to do! And maybe a few you weren't aware of.

The workshop is scheduled for [ day, date, time ] at [ location _ $]$. For more information, or to reserve a place at the workshop, contact [_contact name ].

We look forward to presenting this valuable program to you. Together with your interest and participation, we can make our community a healthier and safer place to live and work.

Sincerely, 


\section{Letter of Invitation for Supporters}

Date

Dear [possible supporting organization],

Home and farm safety and health issues have been the focus of media attention, business promotions, FFA and 4-H youth activities, and Extension programs. These efforts have been very effective in making people more aware of risks and hazards at home or work.

As a community, we all care about the safety and health of our citizens. To this end, we are offering the IMBY Home and Farm Hazard Hunt Workshop, which helps residents develop safety action plans for their own home, acreage, farm, or workplace. (IMBY stands for "In My Back Yard" - the proper place to start practicing safety.)

The IMBY Home and Farm Hazard Hunt Workshop features a motivational video in which a mother tells the true story of the loss of her 11-year-old son in a farm-related incident. After the video, specific ways to improve safety in the home or farm will be presented. Then participants will develop an "action plan" to take home and use with their families.

We ask for your help in bringing this program to our community. Examples of ways you can become involved include:

- Display event advertising posters and brochures

- Encourage customers/members to participate

- Provide in-kind services such as copying or mailing

- Provide time to help administer the program

- Participate on the steering committee

- Provide discounts or monetary support for offering incentives to participants

-... plus many other ideas!

We will soon contact you to discuss this program. If you have any questions or comments, please contact [contact name] at [phone and e-mail info]. We hope you will seriously consider supporting this program in any way possible.

Thank you for your continued support of the well-being of the families in our community. Sincerely, 


\section{Press Release (before event)}

\section{---- For Immediate Release ----}

Date

Contact Person

Phone/E-mail

\section{IMBY PROGRAM ADDRESSES SAFETY HAZARDS \& ISSUES}

The [name of host organization] is sponsoring the "IMBY Home and Farm Hazard Hunt" workshop as a means for local residents to develop a safety action plan that they can apply to their own home, acreage, farm, or workplace - whether rural or urban. (IMBY stands for "in my back yard" - the proper place to start practicing safety.)

The IMBY workshop features a motivational video in which a mother tells the true story of the loss of her 11-year-old son in a farm-related incident. After the video, specific ways to improve safety in the home or farm will be presented. Then participants will develop an "action plan" to take home and use with their families.

The IMBY Home and Farm Hazard Hunt was developed at IFAS at the University of Florida. It is sponsored locally by [name of sponsoring organizations]. The program will be held on [date and time] at [location and town], according to [name and title of official or head of committee].

"We have heard too often about serious injuries and needless deaths. This is a good chance to take a look at the hazards at our homes, acreages, farms, or workplaces and make them safer," says [name, organization, contact info]. [He/She] encourages people to attend the program. Please RSVP no later than [deadline]. 


\section{Press Release (after event)}

\section{For Immediate Release ----}

Date

Contact Person

Phone/E-mail

\section{LOCAL RESIDENTS TAKE ACTION TO PREVENT INJURIES AND DEATHS}

Area residents are taking action to prevent serious injuries and deaths. The "IMBY Home and Farm Safety Hunt" workshop was presented on [date] by [name of sponsoring organization]. The IMBY Home and Farm Safety Hunt was presented as a means for local residents to develop a safety action plan that they can apply to their own home, acreage, farm or workplace - whether rural or urban. (IMBY stands for "In My Back Yard" - the proper place to start practicing safety.)

"This is a great way for me to get over my excuses and start cleaning up hazards," stated [program participant name, town]. "It makes me feel good to know that I am doing something to improve safety for my family," said [name, town]. "Even though we live on a small acreage, we still have many of the same hazards that are on an actual farm. We do have a small tractor and a few horses. We need to know how to work with these things safely."

[Local statistics; first person testimonials can be inserted here or as an adjacent sidebar or article.]

The IMBY Home and Farm Hazard Hunt was developed at IFAS at the University of Florida. The IMBY Hazard Hunt can be found at Florida AgSafe, the Florida Agricultural Safety Program Web site: http://www.flagsafe.ufl.edu. 


\section{Participant's Evaluation}

Please circle the number that most closely represents your opinion about this program.

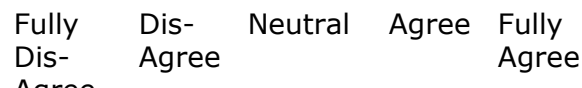

1. The program format was appropriate

$\begin{array}{lllll}1 & 2 & 3 & 4 & 5\end{array}$

2 The information was valuable

$\begin{array}{lllll}1 & 2 & 3 & 4 & 5\end{array}$

3. The incentives to participate

$\begin{array}{lllll}1 & 2 & 3 & 4 & 5\end{array}$

4. The program activities were useful

$\begin{array}{lllll}1 & 2 & 3 & 4 & 5\end{array}$

5. The time it took to complete the program was acceptable

$\begin{array}{lllll}1 & 2 & 3 & 4 & 5\end{array}$

6. The program was good overall

$\begin{array}{lllll}1 & 2 & 3 & 4 & 5\end{array}$

7. I would recommend this program

12

3

$4 \quad 5$

8. What did you like best about the program?

9. What did you like least?

10. What safety changes (will you, did you) make as a result of this program?

(List others on back.)

Please use the back of this sheet for any further comments. Thank you for your time. 

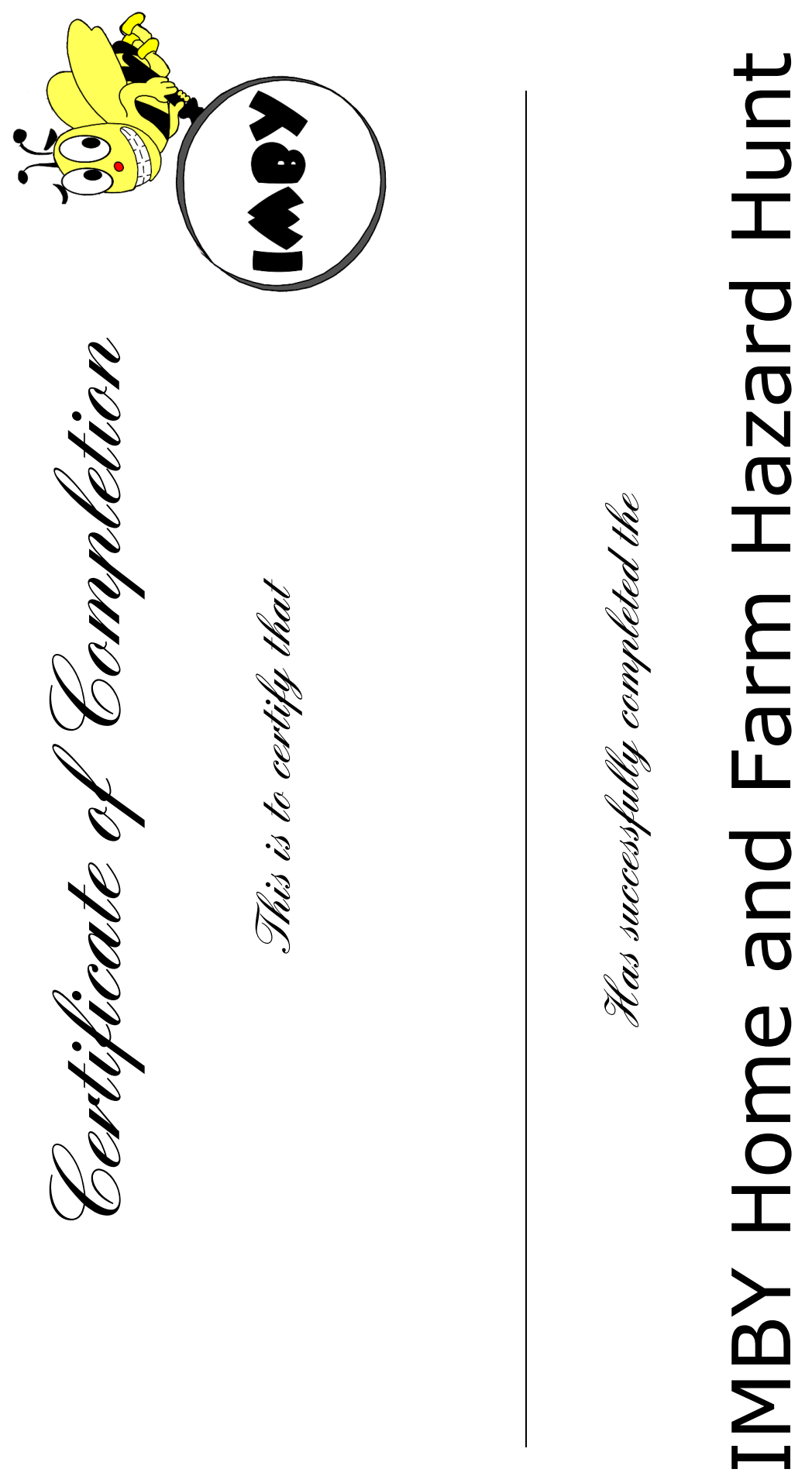


\section{Follow-up Meeting}

Time, place, date of meeting

Chairperson

Other committee members:

\section{Agenda for Follow-Up Meeting:}


Toolkit for Implementing a Community Based "IMBY" Safety Event

\section{Notes}


Toolkit for Implementing a Community Based "IMBY" Safety Event

\section{Notes}

